\title{
AC Impedance Studies on Magnesium Ion Conducting Polymer Electrolyte System with Ethylene Carbonate as Plasticizer and $\mathrm{MgO}$ as Nanofiller
}

\author{
S. SAROJINI* and C. ANJALAI \\ PG and Research Department of Physics, \\ Queen Mary's College (A), Chennai, 600004, India \\ saromkg@gmail.com
}

Received 22 October 2015 / Accepted 20 November 2015

\begin{abstract}
The present investigation involves the electrical characterization studies on three different systems namely system-I $\left((\mathrm{PMMA}+\mathrm{PVDF})_{\mathrm{y}}-\left(\mathrm{Mg}\left(\mathrm{CF}_{3} \mathrm{SO}_{3}\right)_{2}\right)_{1-\mathrm{y}}\right.$, where 1-y $=60,50,40,30$ and $20 \mathrm{~mol} \%$ respectively, System-II $\left((\mathrm{PMMA}+\mathrm{PVDF})_{\mathrm{y}}-\left(\mathrm{Mg}\left(\mathrm{CF}_{3} \mathrm{SO}_{3}\right)_{2}\right)_{1-\mathrm{y}}\right)_{\mathrm{z}}-(\mathrm{EC})_{1-\mathrm{z}}$, where $1-\mathrm{z}=25$, $20,15,10$ and $5 \mathrm{~mol} \%$ respectively and System-III $\left(\left((\mathrm{PMMA}+\mathrm{PVDF})_{\mathrm{y}}-\left(\mathrm{Mg}\left(\mathrm{CF}_{3} \mathrm{SO}_{3}\right)_{2}\right)_{1-\mathrm{y}}\right)_{\mathrm{z}}-(\mathrm{EC})_{1-\mathrm{z}}\right)_{\mathrm{b}}$ - $(\mathrm{MgO})_{1-\mathrm{b}}$, where1-b $=20,15,10$ and $5 \mathrm{~mol} \%$ respectively by solution-casting technique. In system III, the $\mathrm{MgO}$ nanofiller of $32 \mathrm{~nm}$ size prepared by wet chemical sol-gel method is added to arrive at nanocomposite solid polymer electrolyte system in four different compositions namely $1-b=20,15$, 10 and $5 \mathrm{~mol} \%$ respectively. AC complex impedance analysis as a function of frequency was carried out in the frequency range of $20 \mathrm{~Hz}$ to $10 \mathrm{MHz}$ from room temperature to $350 \mathrm{~K}$ to arrive at best conducting composition.
\end{abstract}

Keywords: AC Impedance, Ionic conductivity, Solid polymer Electrolytes

\section{Introduction}

Solid polymer electrolytes exhibit a number of advantages, fast ionic transport in comparison with liquid electrolytes, chemically compatible with electrode materials, possessing good mechanical strength and flexibility as well as leak free ${ }^{1-3}$. For use in solid state batteries, such electrolytes should have high ionic conductivity at ambient, sub-ambient and elevated temperatures, appreciable transference number, good window stabilities and compatibility with the electrodes ${ }^{4}$. Here, our effort has been focused mainly on magnesium ion conducting materials which were found to be reported fairly in literature since last decade $^{5-6}$. Natural abundance of magnesium, its low price and its safety characteristics were advantages. The trifluoromethanesulfonate (triflate) ion, $\mathrm{CF}_{3} \mathrm{SO}_{3}{ }^{-}$, has proved to be an extremely important probe of ionic association in polymer salt complexes.

Hence in our present investigation, in order to achieve high ionic conductivity at ambient temperature, we planned to introduce Magnesium triflate as salt component in the blended 
polymer matrix of PMMA and PVDF. To improve the ionic conductivity at ambient temperature, a plasticizer, Ethylene carbonate (EC) with relatively high dielectric constant has been chosen along with $\mathrm{MgO}$ as nanofiller. The electrical characterization studies in terms of AC impedance studies were intended to the blended matrix of ((PMMA + PVDF $)_{y}$ $\left(\mathrm{Mg}\left(\mathrm{CF}_{3} \mathrm{SO}_{3}\right)_{2}\right)_{1-\mathrm{y}},\left((\mathrm{PMMA}+\mathrm{PVDF})_{\mathrm{y}}-\left(\mathrm{Mg}\left(\mathrm{CF}_{3} \mathrm{SO}_{3}\right)_{2}\right)_{1-\mathrm{y}}\right)_{\mathrm{z}}-(\mathrm{EC})_{1-\mathrm{z}}$ and $\left(\left((\mathrm{PMMA}+\mathrm{PVDF})_{\mathrm{y}}-\right.\right.$ $\left.\left.\left(\mathrm{Mg}\left(\mathrm{CF}_{3} \mathrm{SO}_{3}\right)_{2}\right)_{1-\mathrm{y}}\right)_{\mathrm{Z}^{-}}(\mathrm{EC})_{1-\mathrm{z}}\right)_{\mathrm{b}}-(\mathrm{MgO})_{1-\mathrm{b}}$ in the present investigation.

\section{Experimental}

The pure and blended polymer electrolytes were prepared by solution casting technique. The preparation of the three different systems along with preparation of Mgo nanofiller by wet chemical sol-gel method was discussed elaborately elsewhere ${ }^{7}$.

\section{Characterization studies}

\section{AC impedance analysis}

The complex impedance measurements were carried out using a computer - controlled Germany NOVA control technology NOVA control Alpha-n analyser in the frequency range $20 \mathrm{~Hz}-10 \mathrm{MHz}$ over the temperature range 303-393 K. All the observed impedance plots were best fitted internally by means of the Boukamp equivalent circuit software package incorporated within the computer controlled system. During the present investigation, the frequency response of a variety of compositions of the chosen system was measured in terms of the real $\left(Z^{\prime}\right)$ and imaginary ( $\left.Z^{\prime \prime}\right)$ parts of the complex impedance $\left(Z^{*}\right)$ at different temperatures. The point of intersection of the impedance plots on the real axis in the highfrequency region was taken as the bulk resistance $\left(R_{b}\right)$ of the sample ${ }^{8}$. The electrical conductivity $(\sigma)$ of the sample was estimated using the relationship

$$
\sigma=\frac{t}{R_{b} A}
$$

Where ' $\mathrm{t}$ ' is the thickness of the specimen and A is the area of cross-section.

\section{Results and Discussion}

\section{AC Impedance analysis}

The complex impedance measurements were carried out on film specimens of all the blended polymer system with magnesium triflate salt and plasticized polymer electrolyte system with Ethylene carbonate as plasticizer and $\mathrm{MgO}$ as nanofiller namely ((PMMA + $\mathrm{PVDF})_{\mathrm{y}}-\left(\mathrm{Mg}\left(\mathrm{CF}_{3} \mathrm{SO}_{3}\right)_{2}\right)_{1-\mathrm{y}}$, where $1-\mathrm{y}=60,50,40,30$ and $20 \mathrm{~mol} \%$ respectively and $\left(\left((\mathrm{PMMA}+\mathrm{PVDF})_{50}-\left(\mathrm{Mg}\left(\mathrm{CF}_{3} \mathrm{SO}_{3}\right)_{2}\right)_{50}\right)_{\mathrm{z}}-(\mathrm{EC})_{1-\mathrm{z}}\right.$, where $1-\mathrm{z}=25,20,15,10$ and $5 \mathrm{~mol} \%$ respectively and $\left(\left((\mathrm{PMMA}+\mathrm{PVDF})_{50}-\left(\mathrm{Mg}\left(\mathrm{CF}_{3} \mathrm{SO}_{3}\right)_{2}\right)_{50}\right)_{80}-(\mathrm{EC})_{20}\right)_{\mathrm{b}}-(\mathrm{MgO})_{1-\mathrm{b}}$ where 1-b = $20,15,10$ and $5 \mathrm{~mol} \%$ respectively, in the frequency range $20 \mathrm{~Hz}$ to $10 \mathrm{MHz}$ Accordingly, all the synthesized solid films were loaded with blocking electrode on either side under a stainless steel top electrode with diameter $20 \mathrm{~mm}$ and bottom electrode (diameter $40 \mathrm{~mm}$ ). All the complex impedance measurements were carried out by keeping these solid polymer electrolyte films in between two steel electrodes.

It was established by our research group that pure PMMA specimen exhibits conducting value of $2.4262 \times 10^{-11} \mathrm{Scm}^{-1}$ where as pure PVDF specimen have $2.9625 \times 10^{-11}$ $\mathrm{Scm}^{-1}$ as conducting value at room temperature ${ }^{7}$. The AC impedance study of the synthesized blended solid polymer electrolytes under four different compositions (PMMA) $-(\mathrm{PVDF})_{1-\mathrm{x}}$, where $1-\mathrm{x}=95,90,85$ and $80 \mathrm{~mol} \%$ respectively by our research group revealed that the 
various compositions of this system exhibits electrical conductivity values of the order $10^{-10}$ $\mathrm{Scm}^{-1}$ at room temperature $303 \mathrm{~K}$, particularly composition corresponding to (PMMA) ${ }_{50}$ $(\mathrm{PVDF})_{50}$ exhibits an electrical conductivity value of $4.4496 \times 10^{-10} \mathrm{Scm}^{-1}$ which could be considered as best conducting composition as ((PMMA $\left.)_{50}-(\mathrm{PVDF})_{50}\right)$.

System - I: $(\mathrm{PMMA}+\mathrm{PVDF})_{y}-\left(\mathrm{Mg}\left(\mathrm{CF}_{3} \mathrm{SO}_{3}\right)_{2}\right)_{1-y}$

In order to evaluate the electrical ionic conductivity values, the complex impedance measurements were carried out on film specimens of all the stoichiometric compositions of the system I $(\mathrm{PMMA}+\mathrm{PVDF})_{\mathrm{y}}-\left(\mathrm{Mg}\left(\mathrm{CF}_{3} \mathrm{SO}_{3}\right)_{2}\right)_{1-\mathrm{y}}$ where $1-\mathrm{y}=60,50,40,30$ and $20 \mathrm{~mol} \%$ respectively and their values are shown in Table 1 . It is seen that the various compositions of this system which includes Magnesium triflate as host salt exhibits electrical conductivity values of the order of $10^{-9} \mathrm{Scm}^{-1}$ at room temperature $303 \mathrm{~K}$.

It is noted that, the particular composition (PMMA + PVDF) $)_{50}-\left(\mathrm{Mg}\left(\mathrm{CF}_{3} \mathrm{SO}_{3}\right)_{2}\right)_{50}$, exhibits an electrical conductivity value of $1.559 \times 10^{-8} \mathrm{Scm}^{-1}$ at room temperature $(303 \mathrm{~K})$ which could be considered as best conducting compositions of all the five synthesized samples of the present mixed system. The evaluated electrical conductivity value of this present system establishes the fact that the ionic values are increased by two orders of magnitude which may be the result of the addition of host salt.

Table 1. Room temperature electrical conductivity of obtained for system ((PMMA $)_{50}+$ $\left.(\mathrm{PVDF})_{50}\right)_{\mathrm{y}}-\left(\mathrm{Mg}\left(\mathrm{CF}_{3} \mathrm{SO}_{3}\right)_{2}\right)_{1-\mathrm{y}}$

\begin{tabular}{cc}
\hline Composition $(1-\mathrm{y})$ & $\begin{array}{c}\text { Room temperature electical } \\
\text { onductivity } \sigma, \mathrm{Scm}^{-1}\end{array}$ \\
\hline$\left((\mathrm{PMMA})_{50}+(\mathrm{PVDF})_{50}\right)_{80}-\left(\mathrm{Mg}\left(\mathrm{CF}_{3} \mathrm{SO}_{3}\right)_{2}\right)_{20}$ & $7.689 \times 10^{-9}$ \\
$\left((\mathrm{PMMA})_{50}+(\mathrm{PVDF})_{50}\right)_{70}-\left(\mathrm{Mg}\left(\mathrm{CF}_{3} \mathrm{SO}_{3}\right)_{2}\right)_{30}$ & $3.220 \times 10^{-9}$ \\
$\left.\left((\mathrm{PMMA})_{50}+\mathrm{PVDF}\right)_{50}\right)_{60}-\left(\mathrm{Mg}\left(\mathrm{CF}_{3} \mathrm{SO}_{3}\right)_{2}\right)_{40}$ & $5.590 \times 10^{-9}$ \\
$\left((\mathrm{PMMA})_{50}+(\mathrm{PVDF})_{50}\right)_{50}-\left(\mathrm{Mg}\left(\mathrm{CF}_{3} \mathrm{SO}_{3}\right)_{2}\right)_{50}$ & $1.559 \times 10^{-8}$ \\
$\left((\mathrm{PMMA})_{50}+(\mathrm{PVDF})_{50}\right)_{40}-\left(\mathrm{Mg}\left(\mathrm{CF}_{3} \mathrm{SO}_{3}\right)_{2}\right)_{60}$ & $1.098 \times 10^{-8}$ \\
\hline
\end{tabular}

System -II: $\left((P M M A+P V D F)_{50}-\left(M g\left(\mathrm{CF}_{3} \mathrm{SO}_{3}\right)_{2}\right)_{50}\right)_{z}-(E C)_{1-z}$

The electrical conductivity values obtained at room temperature for five different compositions of the system with the addition of Ethylene carbonate as plasticizer of the present system II viz, $\left((\mathrm{PMMA}+\mathrm{PVDF})_{50}-\left(\mathrm{Mg}\left(\mathrm{CF}_{3} \mathrm{SO}_{3}\right)_{2}\right)_{50}\right)_{\mathrm{z}}-(\mathrm{EC})_{1-\mathrm{z}}$ where $1-\mathrm{z}=25,20$, 15,10 and $5 \mathrm{~mol} \%$ respectively are shown in the Table 2 . It was inferred from the table that different compositions of this present system II with the addition of EC as plasticizer exhibits electrical conductivity of the order of $10^{-8} \mathrm{Scm}^{-1}$ at room temperature $303 \mathrm{~K}$. It is noted that for the particular composition $\left((\mathrm{PMMA}+\mathrm{PVDF})_{50}-\left(\mathrm{Mg}\left(\mathrm{CF}_{3} \mathrm{SO}_{3}\right)_{2}\right)_{50}\right)_{80}-(\mathrm{EC})_{20}$ shows an electrical conductivity value of $2.541 \times 10^{-8} \mathrm{Scm}^{-1}$ at room temperature (303 K) which could be considered as best conducting compositions of all the four synthesized samples of the present mixed system.

System - III: $\left(\left((P M M A+P V D F)_{50}-\left(M g\left(C F_{3} S_{3}\right)_{2}\right)_{50}\right)_{80}-(E C)_{20}\right)_{b}-(M g O)_{1-b}$

Complex impedance measurements were carried out on all film specimens of four different stoichiometric compositions of the polymer electrolyte system III $\left(\left((P M M A+P V D F)_{50}\right.\right.$ $\left.\left.\left(\mathrm{Mg}\left(\mathrm{CF}_{3} \mathrm{SO}_{3}\right)_{2}\right)_{50}\right)_{80}-(E C)_{20}\right)_{b}-(\mathrm{MgO})_{1-b}$ with the addition of $\mathrm{MgO}$ as nanofiller, where 1-b = $20,15,10$ and $5 \mathrm{~mol} \%$ respectively in order to evaluate the electrical ionic conductivity values and tabulated in Table 3.The evaluated values of electrical ionic conductivity values lies in the order of $10^{-6} \mathrm{~S} \mathrm{~cm}^{-1}$ at room temperature $303 \mathrm{~K}$. 
Table 2. Room temperature electrical conductivity of obtained for system ((PMMA + $\left.\mathrm{PVDF})_{50}-\left(\mathrm{Mg}\left(\mathrm{CF}_{3} \mathrm{SO}_{3}\right)_{2}\right)_{50}\right)_{\mathrm{z}}-(\mathrm{EC})_{1-\mathrm{z}}$ where $1-\mathrm{z}=25,20,15,10$ and $5 \mathrm{~mol} \%$ respectively

\begin{tabular}{cc}
\hline Composition $(1-\mathrm{z})$ & $\begin{array}{c}\text { Room temperature Electrical } \\
\text { conductivity } \sigma, \mathrm{S} \mathrm{cm}^{-1}\end{array}$ \\
\hline$\left((\mathrm{PMMA}+\mathrm{PVDF})_{50}-\left(\mathrm{Mg}\left(\mathrm{CF}_{3} \mathrm{SO}_{3}\right)_{2}\right)_{50}\right)_{95}-(\mathrm{EC})_{5}$ & $1.350 \times 10^{-8}$ \\
$\left((\mathrm{PMMA}+\mathrm{PVDF})_{50}-\left(\mathrm{Mg}\left(\mathrm{CF}_{3} \mathrm{SO}_{3}\right)_{2}\right)_{50}\right)_{90}-(\mathrm{EC})_{10}$ & $1.158 \times 10^{-8}$ \\
$\left((\mathrm{PMMA}+\mathrm{PVDF})_{50}-\left(\mathrm{Mg}\left(\mathrm{CF}_{3} \mathrm{SO}_{3}\right)_{2}\right)_{50}\right)_{85}-(\mathrm{EC})_{15}$ & $5.490 \times 10^{-9}$ \\
$\left.\left((\mathrm{PMMA}+\mathrm{PVDF})_{50}-\left(\mathrm{Mg}\left(\mathrm{CF}_{3} \mathrm{SO}_{3}\right)_{2}\right)_{50}\right)_{80}-\mathrm{EC}\right)_{20}$ & $2.541 \times 10^{-8}$ \\
$\left((\mathrm{PMMA}+\mathrm{PVDF})_{50}-\left(\mathrm{Mg}\left(\mathrm{CF}_{3} \mathrm{SO}_{3}\right)_{2}\right)_{50}\right)_{75}-(\mathrm{EC})_{25}$ & $2.096 \times 10^{-8}$ \\
\hline
\end{tabular}

Table 3. Room temperature electrical conductivity values obtained for system III (((PMMA $\left.\left.+\mathrm{PVDF})_{50}-\left(\mathrm{Mg}\left(\mathrm{CF}_{3} \mathrm{SO}_{3}\right)_{2}\right)_{50}\right)_{80}-(\mathrm{EC})_{20}\right)_{\mathrm{b}}-(\mathrm{MgO})_{1-\mathrm{b}}$, where 1-b = 20, 25, 10 and $5 \mathrm{~mol} \%$ respectively

\begin{tabular}{cc}
\hline Composition (1-b) & $\begin{array}{c}\text { Room temperature electrical } \\
\text { conductivity } \sigma, \mathrm{Scm}^{-1}\end{array}$ \\
\hline$\left(\left((\mathrm{PMMA}+\mathrm{PVDF})_{50}-\left(\mathrm{Mg}\left(\mathrm{CF}_{3} \mathrm{SO}_{3}\right)_{2}\right)_{50}\right)_{80}-(\mathrm{EC})_{20}\right)_{80}-(\mathrm{MgO})_{20}$ & $1.43 \times 10^{-7}$ \\
$\left(\left((\mathrm{PMMA}+\mathrm{PVDF})_{50}-\left(\mathrm{Mg}\left(\mathrm{CF}_{3} \mathrm{SO}_{3}\right)_{2}\right)_{50}\right)_{80}-(\mathrm{EC})_{20}\right)_{85}-(\mathrm{MgO})_{15}$ & $6.5 \times 10^{-7}$ \\
$\left.\left(\left((\mathrm{PMMA}+\mathrm{PVDF})_{50}-\left(\mathrm{Mg}\left(\mathrm{CF}_{3} \mathrm{SO}_{3}\right)_{2}\right)_{50}\right)_{80}-(\mathrm{EC})_{20}\right)_{90}-\mathrm{MgO}\right)_{10}$ & $1.29 \times 10^{-6}$ \\
$\left(\left((\mathrm{PMMA}+\mathrm{PVDF})_{50}-\left(\mathrm{Mg}_{2} \mathrm{CFSO}_{3}\right)_{50}\right)_{80}-(\mathrm{EC})_{20}\right)_{95}-(\mathrm{MgO})_{5}$ & $4.58 \times 10^{-7}$ \\
\hline
\end{tabular}

It is noted that for the particular composition $\left(\left((\mathrm{PMMA}+\mathrm{PVDF})_{50}-\left(\mathrm{Mg}\left(\mathrm{CF}_{3} \mathrm{SO}_{3}\right)_{2}\right)_{50}\right)_{80}\right.$ - $\left.(E C)_{20}\right)_{90}-(M g O)_{10}$ which exhibits an electrical conductivity value of $1.26 \times 10^{-6} \mathrm{Scm}^{-1}$ at room temperature $(303 \mathrm{~K})$ could be considered as best conducting compositions of all the four synthesized samples of the present mixed system.

The observed results in terms of electrical conductivity values of the present system strongly attribute the fact that the increase in values of conductivity values of the order of 5 magnitude would be due to the addition of nanofiller $\mathrm{MgO}$ which resulted in high conduction pathways and responsible for the increase of conductivity 9 .

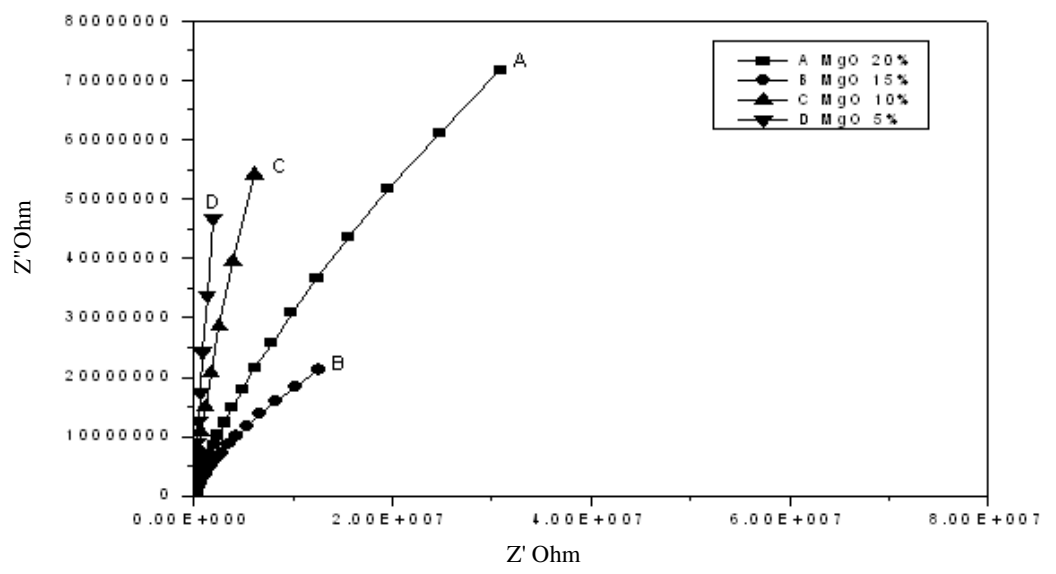

Figure 1. Room Temperature complex impedance plots for (((PMMA+PVDF $)_{50}$ $\left.\left.\left(\mathrm{Mg}\left(\mathrm{CF}_{3} \mathrm{SO}_{3}\right)_{2}\right)_{50}\right)_{80}-(\mathrm{EC})_{20}\right)_{\mathrm{b}}-(\mathrm{MgO})_{1-\mathrm{b}}$, where 1-b = 20, 15, 10 and $5 \mathrm{~mol} \%$ respectively

Hence the aim of our present investigation has been arrived at with in terms of high ionic conductivity values. Figure 1 shows the room temperature complex impedance plots obtained for the four different compositions of the mixed system (((PMMA + PVDF) $)_{50}-$ 
$\left.\left.\left(\mathrm{Mg}\left(\mathrm{CF}_{3} \mathrm{SO}_{3}\right)_{2}\right)_{50}\right)_{80}-(\mathrm{EC})_{20}\right)_{\mathrm{b}}-(\mathrm{MgO})_{1-\mathrm{b}}$, where 1-b $=20,15,10$ and $5 \mathrm{~mol} \%$ respectively. The observed impedance plots are depressed semicircles with the $\mathrm{x}$-axis as generally observed for polymer electrolyte systems ${ }^{10}$.

\section{Conclusion}

The best electrical conductivity of the system $\left(\left((\mathrm{PMMA}+\mathrm{PVDF})_{\mathrm{y}}-\left(\mathrm{Mg}\left(\mathrm{CF}_{3} \mathrm{SO}_{3}\right)_{2}\right)_{1-\mathrm{y}}\right)_{\mathrm{z}}-\right.$ $\left.(\mathrm{EC})_{1-\mathrm{z}}\right)_{\mathrm{b}}-(\mathrm{MgO})_{1-\mathrm{b}}$, where $1-\mathrm{b}=20,15,10$ and $5 \mathrm{~mol} \%$ was found to be $1.29 \times 10^{-6} \mathrm{Scm}^{-1}$ optimized with $5 \mathrm{~mol} \% \mathrm{MgO}$. Hence we were able to achieve the increase in conductivity of the order of 5 magnitudes which shows the ability of the synthesized system as ion conducting polymer electrolyte and demonstrated their use as solid electrolytes for ambient temperature solid state device applications.

\section{Acknowledgement}

The authors would like to thank low temperature lab, IIT, Madras for AC impedance analysis and UGC, New Delhi for the financial support received in the form of a minor research project (Dr.S.Sarojini, No.F MRP-5226/14 (SERO/UGC) in Dept. of Physics, Queen Mary's College (A), Chennai-4, India.

\section{References}

1. Anji Reddy Polu, Ranveer Kumar and Vijaya Kumar K, Adv Mat Lett., 2012, 3(5), 406-409; DOI:10.5185/amlett.2012.6375

2. Kambila Vijay Kumar, J Petroleum Technol Altern Fuels, 2011, 2(1), 11-20.

3. Senthil J, et al. Inter J Engg Sci Tech (IJEST), 2011, 3, 6316.

4. Kamlesh Pandey, Markandey Singh and Nidhi Asthana, Mrigank Mauli Dwivedi and Agrawal S L, Inter J Mater Sci., 2011, 1, 9-17; DOI:10.1134/S1023193513060116

5. Ammakutti N, Karuppasamy K and Balakumar S, et al., Chem Sci Trans., 2012, 1(2), 311-316; DOI: $10.7598 /$ cst2012.198

6. Zainol N H, Osman Z, Othman L and Isa K B Md, Adv Mater Res., 2013,. 686, 137-144.

7. Sarojini S and Anjalai C, Chem Sci Trans, 2015, 5(1); DOI: 10.7598/cst2016.1158

8. Padmasree K P, Kanchan K D, Panchal H R, Awasthi A M and Bharadwaj S, Solid State Commun., 2005, 136(2), 102-107; DOI:10.1016/j.ssc.2005.06.011

9. Arulsankar A, Kulasekarapandian K, Jeya S, Jayanthi S and Sundaresan B, IJIRSET, 2013, 2(9), 4883-4890.

10. Sownthari K and Suthanthiraraj S A, eXPRESS, Polymer Lett., 2013, 7(6), 495-504; DOI:10.3144/expresspolymlett.2013.46 